\title{
Single Tuned Harmonic Shunt Passive Filter Design for Suppressing Dominant Odd Order Harmonics in order to Improve Energy Efficiency
}

\author{
Mansoor Ahmed Soomro*, Anwar Ali Sahito, Irfan Ahmed Halepoto and Kamran Kazi \\ Department of Electrical Engineering, MUET, Jamshoro, Sindh, Pakistan; engr.masoomro@gmail.com
}

\begin{abstract}
Power quality refers to the provision of the clean and stable electrical power supplies with least interruptions of current and voltage However, power quality problems arise due to the application of nonlinear loads with end user devices. Electrical installations majorly suffer from adverse effects of harmonic currents and voltages. Though, this problem has been decades long and pattern of investigation for the researchers but due to evolution of semiconductor technology, it has become burning issue with reference to the power system loads. Therefore, it becomes necessary to mitigate these harmonics for the safe operation of electrical appliances. Thus, harmonic passive filters are cost effective and easy to implement. In this work, the mitigation of current harmonics has been accomplished through single tuned Shunt Harmonic Passive Filter (SHPF). Furthermore, the application of six pulse multiplication converter technique ensures the mitigation of dominant $3^{\text {rd }}$ harmonic currents and reduction of succeeding $5^{\text {th }}$ and $7^{\text {th }}$ harmonic currents. Furthermore, shunt operation of single tuned harmonic passive filter enables the current to follow the low impedance path. Consequently, the current harmonic distortion becomes less than $5 \%$ according to allowable IEEE 519-1992 standards. This reduction in harmonic distortion not only reduces the losses incurred in the system but it also improves the energy efficiency of the electrical Power Distribution System (PDS).
\end{abstract}

Keywords: IEEE 519 -1992 Standards, Energy Efficiency,Passive Harmonic Filters, Power Quality, Single Tuned Shunt Harmonic Passive Filter,Six Pulse Multiplication Converter

\section{Introduction}

Electrical power system is aimed to generate electricity and deliver it to the end user machines and equipmen ${ }^{1}$. It ensures power quality so that the regulation and stability in power supplies is created with least interruptions of current and voltage ${ }^{2}$. It means incorporation of power system reliability at an acceptable cost. Electrical energy is wasted because of heat loss in electrical power transmission and distribution which accompanies inefficient and out-dated technology. Power quality problems also include harmonic disturbances that severely affect the reliability of power system ${ }^{3}$.It increases frequency level which exceeds the base frequency $(50 \mathrm{~Hz} / 220 \mathrm{~V}$ or 60 $\mathrm{Hz} / 120 \mathrm{~V}$ ) values.

$$
\mathbf{f}_{\mathrm{h}}=\mathbf{h} \times \mathbf{f}_{\mathrm{f}}
$$

where;

$\mathrm{f}_{\mathrm{h}}=$ Harmonic frequency (for $3 \mathrm{rd}$, 5th, 7th harmonic and so on)

$\mathrm{h}=$ Integer value

$\mathrm{f}_{\mathrm{f}}=$ Fundamental frequency (i.e $50 \mathrm{~Hz}$ )

As a result of harmonic distortion, supply current as well as supply voltage level is significantly varied from its accepted limits. These effects are generally known as Total Harmonic Current Distortion (THDi) and Total Harmonic Voltage distortion (THDv) respectively.

$$
T H D_{i}=\frac{\sqrt{I_{2}^{2}+I_{3}^{2}+I_{4}^{2}+\cdots I_{n}^{2}}}{I_{1}} \times 100
$$

And, 


$$
T H D_{v}=\frac{\sqrt{V_{2}^{2}+V_{3}^{2}+V_{4}^{2}+\cdots V_{n}^{2}}}{V_{1}} \times 100
$$

It is worth mentioning to quote that sinusoidal currents and voltages have $T H D_{\square}$ of zero value.

Harmonic current and voltage disturbances badly affect the electrical installations. The contributors of harmonic disturbances involve single phase loads (e.g. DC converters, static VAR compensators, Switched Mode Power Supplies (SMPS), rectifiers) and three phase loads (e.g. adjustable speed drives and large uninterrupted power supplies). Third harmonic is the most dominant and it causes serious damages to the electrical machines and equipment. The effects include Overloading of power factor correction capacitors, electromagnetic interference in cables, Congestion of neutrals, Warmth of transformers, Nuisance tripping of circuit breakers ${ }^{4}$. Therefore, it becomes necessary to mitigate these harmonics for the safe operation of electrical appliances. In this context, a variety of harmonic mitigation methods have been used like Active ${ }^{5}$, passive ${ }^{6,7}$ and hybrid filters ${ }^{8}$. Active filters are used in many electrical installations but it is costly and complex in design to implement. Thus, harmonic passive filters are cost effective and easy to implement.

In this work, single tuned SHPF has been used along with six pulse multiplication converter technique to suppress current harmonic disturbances. The six pulse harmonic injection ensures the mitigation of $3^{\text {rd }}$ harmonic currents and reduction of succeeding $5^{\text {th }}$ and $7^{\text {th }}$ harmonic currents ${ }^{9}$. Furthermore, shunt operation of single tuned harmonic passive filter enables the current to follow the low impedance path. Consequently, the current harmonic distortion becomes less than allowable IEEE 519 -1992 standards ${ }^{10}$.

\section{Shunt Harmonic Passive Filter (SHPF)}

A single tuned Shunt Harmonic Passive Filter (SHPF) as shown in Figure 1(a) is generally a series RLC circuit configured in parallel arrangement with the AC to DC converter. Its application ensures low impedance path to the harmonic currents flowing into the PDS connected with nonlinear loads ${ }^{11}$. The Impedance - frequency characteristics shown in Figure 1(b) describe that impedance value exponentially decreases with the increase in the frequency and it ceases at $5^{\text {th }}$ harmonic frequency. But later on, it linearly increases for higher frequencies.

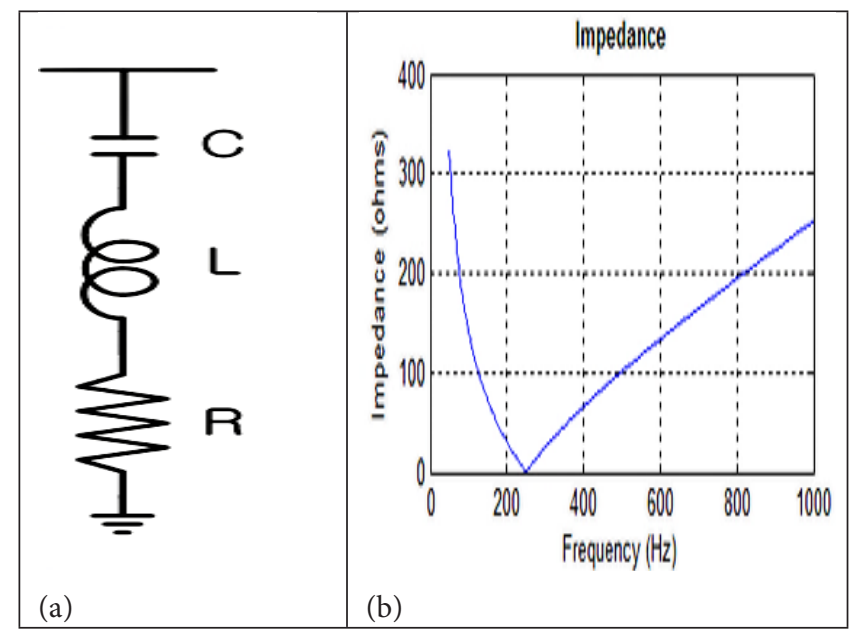

Figure 1. (a) The schematic diagram of SHPF and (b) Impedance- frequency characteristics of shunt harmonic passive filter.

The passive harmonic filters in shunt arrangement recompense the reactive power to increase power quality of the system. Therefore, this arrangement requires capacitor bank of small values (i.e. in micro farads) to correct the applied load power factor ${ }^{12}$.

The magnitude of capacitance applied for capacitor bank can be found as;

whereas;

$$
C=\frac{1}{2 \pi f X_{c}}
$$

$$
X_{C}=\frac{V^{2}}{Q}
$$

The small value of capacitor ensures low reactive power incurred in the system and therefore, allowing more active power to facilitate the loading conditions at reasonable power factor $\frac{13}{3}$. In this way, the shunt passive filter principally depends upon the source impedance. Furthermore, shunt passive filter diverts the distorted currents at tuned frequency given by;

$$
f_{r}=\frac{1}{2 \pi \sqrt{L C}}
$$

At tuned frequency,

$$
X_{L}=X_{C}
$$

Because, impedance value is given by formula;

$$
Z=\sqrt{R^{2}+\left(X_{l}-X_{C}\right)^{2}}
$$

Therefore,

$$
Z=R
$$


Then, Impedance value will be low and suitable to eliminate the dominant harmonic currents flowing into the system. Consequently, power quality will be increased at improved power factor.

\section{Significance of IEEE 519 - 1992 Standards}

IEEE 519 -1992 standards are designed to set the limits of current and voltage harmonic injection onto the power system for individual customers so that the resulting distortion level is acceptable to all the customers of electric utility ${ }^{14}$. The measurement of these harmonics is done at the point of Common Coupling (CPP) which differentiates between linear and nonlinear load. IEEE 519 guidelines limit the $T H D_{i}$ and $T H D_{v}$ values extended up to $5 \%$ only ${ }^{15}$. This standard recognizes the responsibility of the customer to refrain from degrading the supply voltage and the current levels of the utility by drawing heavy nonlinear or distorted currents ${ }^{16}$.

\section{Energy Efficiency}

The energy efficiency is the minimum possible use of energy for the similar performance of service required. The harmonic filtering increases energy efficiency of the power distribution system. The variety of electrical and electronic equipment generate harmonic disturbances on supply side. The effects of harmonic disturbances become significant in terms of transient over voltages, abnormal signaling of protection relays and frequent switching of circuit breakers. It results in heat, vibration, undue smoke thereby reducing the efficiency and service life of equipment. The inclusion of passive Harmonic filtering technique makes energy system efficient which can be mathematically described by following expression;

$$
\begin{aligned}
\text { Energy Efficiency } & =(\text { Energy output/ energy input }) \times 100 \\
& =(14.06 / 15.55) \times 100 \\
& =90.41 \%
\end{aligned}
$$

This energy efficiency is sufficient to propose appropriate working of the three phase distribution system when used with three phase AC to DC converters. This energy efficiency can reduce the energy provided from national grid by $10 \%$ or more up to 2010 and developed countries like US and European countries are trying to increase this value by $20 \%$ up to 2020 .

\section{Proposed Harmonic Mitigation Technique}

The proposed technique involves conjunction of single tuned shunt passive filter with six pulse bridge converter circuit. The hardware model as shown in Figure 2 is designed to give real time data. It allows the researchers to accurately and efficiently simulate the power distribution system. The circuit components include three phase AC supply, three phase isolation transformer, six pulse bridge converter circuit, power quality analyser, line reactors, capacitor bank and nonlinear load. The isolation transformer insulates the input power supply from the load. Furthermore, line reactors are basically current limiting reactors which not only perform the function of limiting the short circuit current but they also filter the spikes of the current. Capacitor bank is provided to provide compensation of reactive power and to increase the load power factor. Besides, power quality analyzer is used to measure all aspects of power and power quality particularly voltage, current and frequency. Additionally, it measures the THD values of current and voltage by showing their spectrograph. Harmonics basically appear due to the application of nonlinear loads which are severe and need mitigation so as to maintain the reliability and efficiency of the PDS.

\section{Results and Discussion}

In this section, response of six pulse converter is presented by applying nonlinear loads. The results are taken before

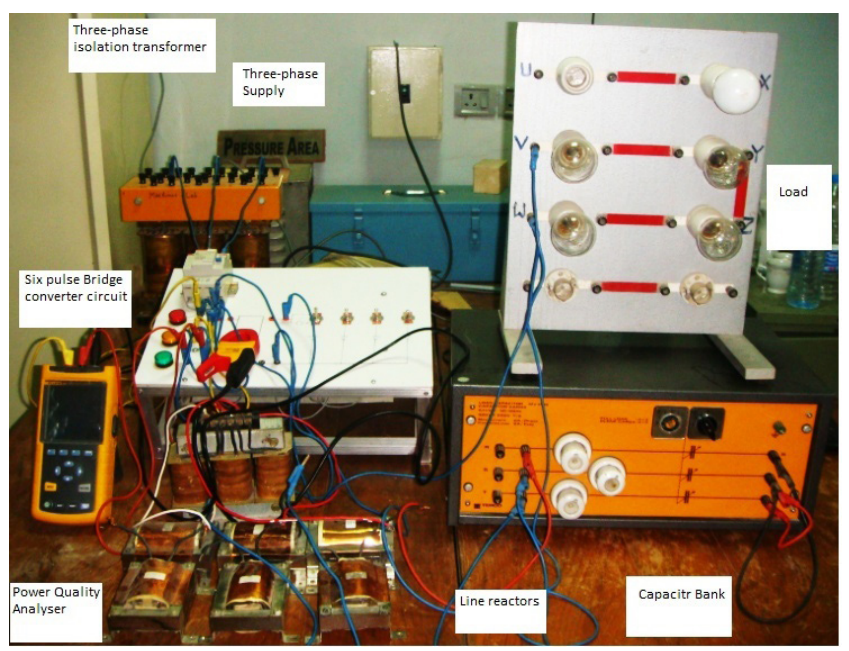

Figure 2. Proposed hardware model for current harmonic mitigation. 


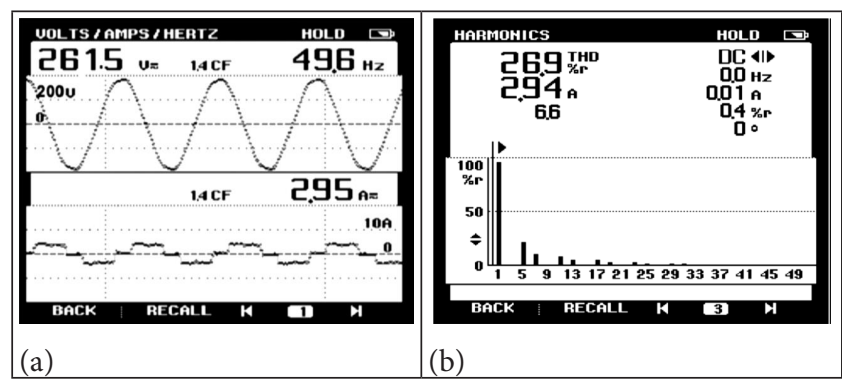

Figure 3. (a) AC mains supply voltage and current waveform and the response of spectrograph showing the elimination of 3 rd harmonic currents.

and after the compensation of harmonic passive filter. In the first approach, six pulse converter techniques are applied for the elimination of dominant harmonics. The characteristics of this technique enable the elimination of 3rd harmonics but successive harmonics are at high value. Figure 3 (a) shows that voltage waveform is sinusoidal but current waveform contains harmonics. Though, they have been limited in its severity yet their existence cannot be tolerated. The results are measured by using power quality analyzer. It demonstrates that current is limited to $2.95 \mathrm{~A}$ and crest factor is in normal limits i.e. 1.4 CF. Furthermore, spectrograph shown in Figure 3 (b) suggests that 3rd harmonics is eliminated but 5th and 7th harmonics exists which are beyond the scope of six pulse converter. Therefore, totals current harmonic distortion( $T H D i$ ) value is $26.9 \%$ which is unacceptable under IEEE 519 recommended practices of harmonic mitigation.

So, in the second approach, an analysis of (THDi) was made and after concentrated thought it was decided to include shunt harmonic passive filter (SHPF) in addition to six pulse AC - DC converter. This approach worked well. Figure 4(a) shows that both current and voltage wave are approaching to sinusoidal shape which ensures that distortion of current is under normal limits which was disturbed due to the application of nonlinear loads. The value of current is same as before i.e. $2.48 \mathrm{~A}$ and the crest factor of $1.5 \mathrm{CF}$ is also acceptable. Additionally, spectrograph as shown in Figure 4(b) shows that (THDi) value is $4.8 \%$ which is in the range of IEEE $519-1992$ recommended standards.

\section{Conclusion}

Power quality problems majorly include harmonic disturbances that severely affect the reliability of power system.

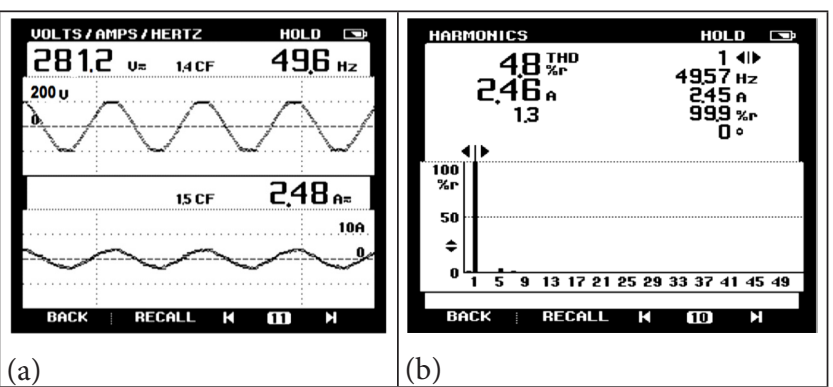

Figure 4. (a) shows the sinusoidal AC mains supply current and voltage waveform and (b) indicates the spectrograph showing THD $i$ value below IEEE 519 standards.

Third harmonic is the most dominant and it causes serious damages to the electrical machines and equipment. Therefore, it becomes necessary to mitigate these harmonics for the safe operation of electrical appliances. Therefore, the proposed technique of six pulse multiplication converter with shunt passive filter was employed. The six pulse converter successfully eliminated the severe $3 \mathrm{rd}$ harmonic currents and the shunt passive filter reduced the THDi values to acceptable IEEE 519-1992 specifications. Furthermore, the shunt arrangement of passive filters compensates the reactive power to improve power quality of the system. The measurement of these harmonics is done at the point of CPP which differentiates between linear and nonlinear load. IEEE 519-1992 guidelines limit the THD $i$ and THD $v$ value extended up to $5 \%$ only. The obtained results were in full conformity with the recommended IEEE standards.

\section{Acknowledgement}

The completion of this research work was not possible without the technical and logistic support from calibration Lab, Department of Electrical Engineering, MUET, Jamshoro, Pakistan. Therefore, authors pay gratitude for necessary arrangements.

\section{References}

1. Sahito AA., Halepoto IA., Uqaili MA., Memon ZA., Larik AS, Mahar MA. Analyzing the impacts of distributed generation integration on distribution network: A corridor towards smart grid implementation in Pakistan. Wireless Personal Communications, Springer; 2015.p. 545-63.

2. Kuldeep KS, Anand VP.Harmonics andits mitigation technique by passive shunt filter. 2013; 3(2):2231-307. 
3. Soomro MA, Halepoto IA, Sahito AA. Design of six pulse bridge multiplication converter model for current harmonic elimination of three phase AC-DC converter. Mehran University Research Journal of Engineering and Technology. 2014; 33(4):476-84.

4. Gour S, Gupta S. Comparative analysis of multipulse AC-DC converter using zig-zag transformer.2013 Jul; 3:38-42.

5. Sharma V, Tomer AS.Comparative analysis on control methods of shunt active power filter for harmonics mitigation. International Journal of Science and Research. 2014; 3(2):107-14.

6. Soomro MA, Uqaili MA, Memon ZA.A novel method for the current harmonic elimination of industrial power system using single tuned shunt passive filter. Mehran University Research Journal of Engineering and Technology. 2012 Jan; $31: 1$.

7. Zubi HM, Dunn RW, Robinson FVP.Comparison of different common passive filter topologies for harmonic mitigationUPEC 2010 Aug 31-Sep 3; 2010.

8. Napoles J, Leon JI, Portillo R, Franquelo LG, Aguirre MA.Selective harmonic mitigation technique for highpower converters. IEEE Transactions on Industrial Electronics. 2010; 57(7):2315-23.
9. Peterson M, Singh B.Multipulse controlled ac-dc converters for harmonic mitigation and reactive power management. IET Power Electronics. 2009; 2(4):443-55.

10. Halpin SM.Harmonic modeling and simulation requirements for the revised IEEE standard 519-1992. IEEE General Meeting on Power Engineering Society. 2003; 2.

11. Wouter RA, Jozef AL, Ghijselen AA, Melkebeek J. Harmonic mitigation potential of shunt harmonic impedances; 2002. p.63-9.

12. Yousif SN, Wanik MZC, Mohamed A. Implementation of different passive filter designs for harmonic mitigation. PECon 2004. Proceedings. National Power and Energy Conference;2004. p.229-31.

13. Das JC.Passive filters-potentialities and limitations. IEEE Transactions On Industry Applications. 2004 Jan/Feb; 40(1):232-41.

14. Recommended Practice and Requirements for Harmonic Control in Electrical Systems, IEEE Std. 519; 1992.

15. Wu CJ, Liao CJ.Investigation and mitigation of harmonic amplification problems caused by single-tuned filters.IEEE Transactions on Power Delivery. 1998 Jul; 13(3):800-6.

16. Arrillaga J, Bradley DA, Bodger PS. Power System Harmonics. American Scientific Publishers: New York, Wiley; 1985. 